TIP Periodica Polytechnica

Chemical Engineering

59(1), pp. 51-58, 2015

DOI:10.3311/PPch.7308

Creative Commons Attribution (i)

RESEARCH ARTICLE

\section{Sugar-based Crown Ethers in Enantioselective Syntheses}

\author{
Péter BAKÓ ${ }^{1 *}$, Zsolt RAPI ${ }^{1}$, György KEGLEVICH ${ }^{1}$
}

RECEIVEd 27 JANUARY 2014; ACCEPTED AFTER REVISION 06 MAY 2014

\begin{abstract}
A number of chiral macrocyclic compounds have been prepared that contain a monosaccharide-derived sub-unit. These sugar-based crown ethers were used as chiral phase transfer catalysts in a few asymmetric reactions. A few of them proved to be effective catalysts in Michael additions, a Darzens condensation and an epoxidation of $\alpha, \beta$-enones. It was found that the type of the monosaccharide, the substituents on the sugar unit and on the nitrogen atom of the macroring have a significant influence on both the yield and the enantioselectivity.
\end{abstract}

\section{Keywords}

chiral crown ethers, phase transfer catalysis, asymmetric reactions

\footnotetext{
${ }^{1}$ Department of Organic Chemistry and Technology, Faculty of Chemical Technology and Biotechnology, Budapest University of Technology and Economics, H-1521 Budapest, Hungary
}

* Corresponding author, e-mail: pbako@mail.bme.hu

\section{Introduction}

The synthesis and investigation of sugar-based crown ethers was an interesting and up to date topic in the last decades at our department. The basis of our research is the finding that the chiral crown ethers incorporating monosaccharide moiety in their ring, are able to generate asymmetric induction as chiral phase transfer (PT) catalysts in certain reactions. Phase transfer catalysis has been recognized as a versatile methodology for organic synthesis, based on its simple experimental operations, mild reaction conditions using inexpensive and environmentally benign reagents and solvents (very often water). A few of chiral PT catalysts have been successfully used in asymmetric reactions. Chiral phase transfer catalysis has become an attractive area in the ,green" chemical discipline, and many types of chiral catalysts have been developed and applied over the past few decades [1-3].

Crown ethers with carbohydrate moieties form a special group of the chiral PT catalysts. Sugars are suitable source of chirality and their basic chemistry is well explored. They are available in enantiomerically pure form with known chiroptical properties. Carbohydrates are unusually well-endowed with functionality which can be used to build in secondary binding sites, as well as catalytic sites. A part of the starting monosaccharides is easily available commercial product. Crown ethers containing a sugar unit incorporated in the macrocyclic ring may be built from various monosaccharides; thus macrocycles of different chirality are available [4-5].

\section{Results and discussion}

We have synthesized a variety of chiral crown ethers containing one sugar unit in annelation with the macrocyclic ring from various monosaccharides such as D-glucose, D-mannose, D-galactose, D-altrose, 2-deoxy-D-ribo-hexopyranoside, L-arabinose and from sugar alcohols as L-treitol, D-mannitol. These macrocycles differed significantly from each other by the chirality of the sugar units, the size of macrocyclic ring and the number and sort of the heteroatoms in the crown ring. The most important types of the sugar-based crown ethers developed by us can be seen in Fig. 1. 


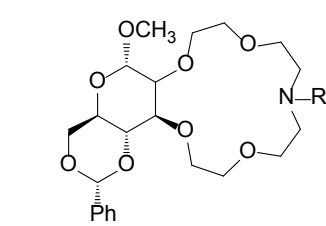

$1 \alpha$-D-glucopyranoside unit $2 \mathrm{C}$ -

$2 \alpha$-D-mannopyranoside unit $2 \mathrm{C}-\mathrm{O}$

$\mathrm{R}=\mathrm{H}$, alkyl, aralkyl, alkoxy

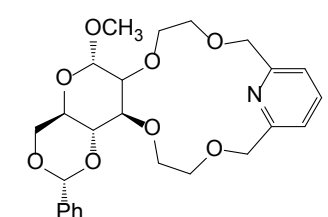

$6 \alpha$-D-glucopyranoside unit $2 \mathrm{C}$ -

$7 \alpha$-D-mannopyranoside unit $2 \mathrm{C}-\mathrm{O}$

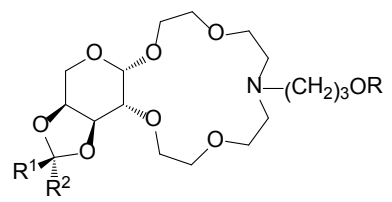

3a $\mathrm{R}=\mathrm{H}, \mathrm{R}^{1}=\mathrm{R}^{2}=\mathrm{CH}_{3}$ 3b $\mathrm{R}=\mathrm{CH}_{3}, \mathrm{R}^{1}=\mathrm{R}^{2}=\mathrm{CH}_{3}$ 3c $R=R^{1}=H, R^{2}=P h$

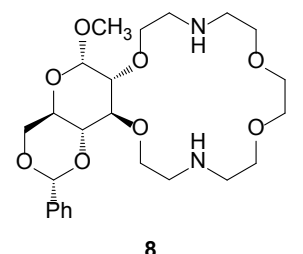

8

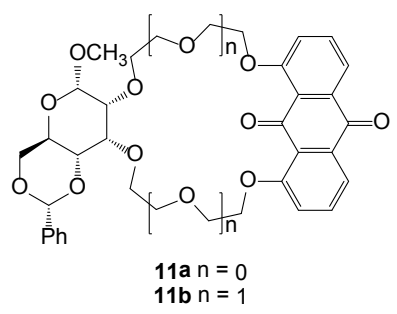<smiles>[R1]C1O[C@H](OC)C[C@@H]2OCCOCCN(C)CCOCCO[C@H]12</smiles>

4a $\mathrm{R}=\mathrm{H}, \mathrm{R}^{1}=\mathrm{CH}_{3}$

4b $\mathrm{R}=\mathrm{CH}_{3}, \mathrm{R}^{1}=\mathrm{CH}_{3}$ 4c $\mathrm{R}=\mathrm{H}, \mathrm{R}^{1}=\mathrm{CH}_{2} \mathrm{O} p-\mathrm{C}_{6} \mathrm{H}_{4} \mathrm{OCH}_{3}$ 4d R $=\mathrm{CH}_{3}, \mathrm{R}^{1}=\mathrm{CH}_{2} \mathrm{O} p-\mathrm{C}_{6} \mathrm{H}_{4} \mathrm{OCH}_{3}$

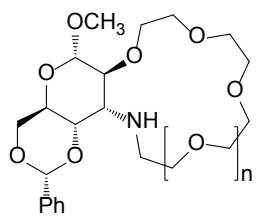

5a $n=1$

$5 \mathrm{~b} n=2$

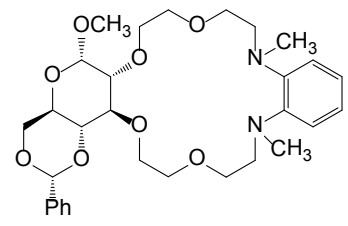

9

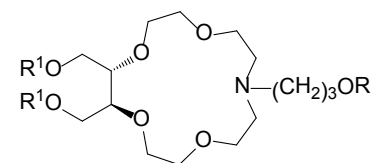

10a $\mathrm{R}=\mathrm{H}, \mathrm{R}^{1}=\mathrm{Bn}$

10b $\mathrm{R}=\mathrm{CH}_{3}, \mathrm{R}^{1}=\mathrm{Bn}$ 10c $\mathrm{R}=\mathrm{H}, \mathrm{R}^{1}=\mathrm{CH}_{3}$ $\operatorname{10d} \mathrm{R}=\mathrm{CH}_{3}, \mathrm{R}^{1}=\mathrm{CH}_{3}$

Fig. 1 Monosaccharide-based chiral crown ethers

Monoaza-15-crown-5 type macrocycles annelated to protected monosaccharides with different side arms (with heteroatoms at the end) on the nitrogen atom of the crown ring, were synthesized in many steps $(\mathbf{1 - 4}, \mathbf{1 0})$. This type of macrocycles named lariat (lasso) ethers or armed crown ethers having heteroatom containing podand arms are suitable to be involved in encapsulated complexation and display high lipophilic character and unique guest specificity due to the macroring - side arm cooperativity [6-7].

The synthesis of methyl- $\alpha$-D-glucopyranoside- and methyl$\alpha$-D-mannopyranoside-based lariat ethers $(\mathbf{1}, \mathbf{2})$ [8], crown ethers consisting L-arabinose units (3) [9], 2-deoxy-ribo-hexopyranoside- and altrose-based macrocycles $(4,5)$ [10] and D-glucose- and D-mannose-based monoaza-15-crown-5 compounds with pyridine-ring $(6,7)[11]$ were published by us in the last years. In addition, diaza crown ethers having 15- and 18-membered ring which contained secondary and tertiary amino groups $(\mathbf{8}, 9)$, monoaza-15-crown-5 type compounds with L-treitol units (10), and glucopyranoside-based macrocycles containing 9,10-anthraquinone or acridine fluorescent signalling units $(\mathbf{1 1}, \mathbf{1 2})$, have also been synthesized [12].

In all cases, first a protected monosaccharide derivative with two free vicinal hydroxyl groups was prepared, then the crown ring was built up on the hydroxyl groups of the compound. The preparation of lariat ethers is shown via the example of the 2-deoxy-ribo-hexopyranoside-based macrocycles (4) (Fig. 2) [10].
The synthesis of one of the key compounds (16) involves the opening of the benzylidene acetal ring of 2,3-anhydro derivative 13 that was performed with $N$-bromosuccinimide (NBS). The benzoyl group of the intermediate was removed by reaction with sodium methylate in methanol to provide bromo sugar $\mathbf{1 4}$. The bromo function of intermediate 14 was removed by hydrogenolysis in the presence of $\mathrm{Pd} / \mathrm{C}$ to give species $\mathbf{1 5}$. The regioselective reductive ring opening was accomplished by $\mathrm{LiAlH}_{4}$ in THF to afford methyl 2,6-dideoxy- $\alpha$-D-ribo-hexopyranoside (16).

Another key compound (19) was prepared by the reductive ring opening of 2,3-anhydro derivative 13 carried out with tetrabutylammonium tetrahydroborate $\left(\mathrm{Bu}_{4} \mathrm{NBH}_{4}\right)$ leading to the diaxial ring opening product, methyl 4,6-O-benzylidene2-deoxy- $\alpha$-D-ribo-hexopyranoside (17). Removal of the benzylidene acetal moiety in compound $\mathbf{1 7}$ was performed by catalytic hydrogenation to furnish methyl-2-deoxy- $\alpha$-D-ribohexopyranoside (18). Selective protection of the C-6 hydroxyl group was achieved by the Mitsunobu reaction using 4-methoxyphenol, diisopropyl-azodicarboxylate and triphenyl phosphine (19). The vicinal hydroxyl groups of compounds 16 and 19 were alkylated with bis(2-chloroethyl) ether in the presence of tetrabutylammonium hydrogensulfate $\left(\mathrm{Bu}_{4} \mathrm{HSO}_{4}\right)$ as the catalyst and $50 \%$ aq. $\mathrm{NaOH}$ as the base in a liquid-liquid two-phase system to give intermediates $\mathbf{2 0}$ and $\mathbf{2 1}$ in $\mathbf{4 5} \%$ and $52 \%$ yields, respectively, after chromatography. The exchange of chlorine to iodine in intermediates $\mathbf{2 0}$ and $\mathbf{2 1}$ was accomplished by reaction with $\mathrm{NaI}$ in boiling acetone to afford bis-iodo derivatives 
<smiles>CO[C@H]1C[C@@H](O)[C@@H](O)[C@@H](C)O1</smiles>

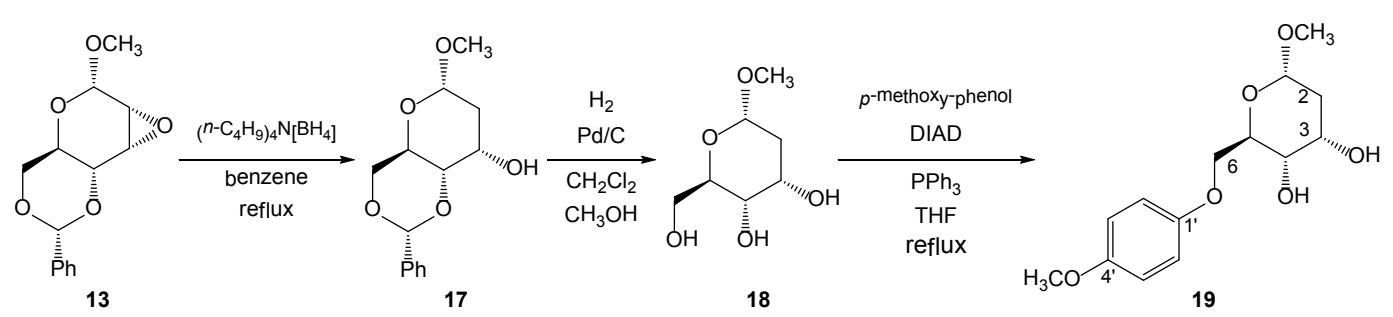

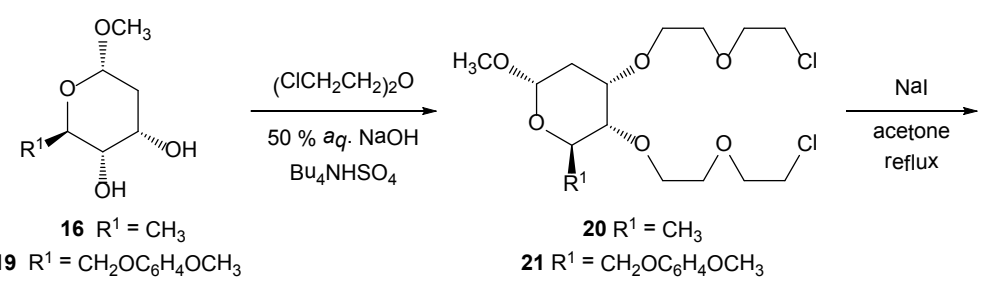

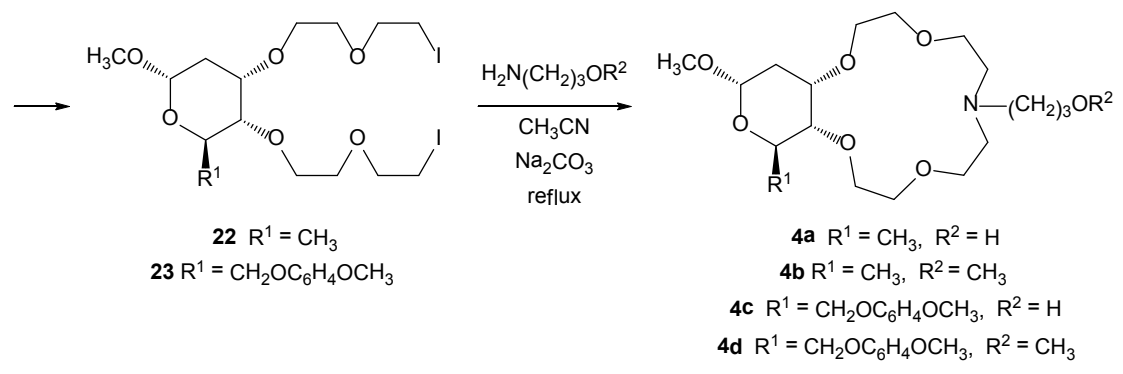

Fig. 2 Preparation of 2-deoxy-ribo-hexopyranoside-based lariat ethers 4a-d<smiles>CC(C)C(=O)/C=C/[Ga]</smiles>

Fig. 3 Asymmetric addition of 2-nitropropane (25) to $\alpha, \beta$-enones (24)

22 and 23, respectively. These compounds were then cyclized with two kinds of primary amines, such as 3-aminopropanol and 3-methoxypropylamine, in boiling acetonitrile, in the presence of dry $\mathrm{Na}_{2} \mathrm{CO}_{3}$ to furnish azacrown ethers $4 \mathbf{a}-\mathbf{b}$ and $\mathbf{4 c - d}$, respectively. It is interesting to note that the yields of 2,6-dideoxy-ribohexopyranoside-based lariat ethers (4a and $\mathbf{4 b}$ ) were relatively low (46\% and $30 \%$, respectively), while those of the macrocycles having $p$-methoxyphenyl substituent (4c and 4d) were much higher (79\% and $84 \%$, respectively) [10].

\subsection{Enantioselective reactions}

The sugar-based crown ethers were used as chiral phase transfer catalysts in a few asymmetric reactions. A few of them proved to be efficient catalyst in two Michael additions, in a Darzens condensation and in the epoxidation of $\alpha, \beta$-enones. It was found that the type of the monosaccharide, the substituents on the sugar unit and on the nitrogen atom of the macroring have had a significant influence on both the yield and the enantioselectivity [5].

The two Michael additions used as model reactions were performed in solid-liquid phase at room temperature. The addition of 2-nitropropane (25) to $\alpha, \beta$-enones (24) was carried out in dry toluene, in the presence of solid sodium tert-butoxide (35 mol\%) and one of the chiral catalysts (7 mol\%). (Fig. 3) $[5,8-9,11,13]$.

Choosing chalcone (24a, $\left.\mathrm{Ar}^{1}=\mathrm{Ar}^{2}=\mathrm{Ph}\right)$ as the starting material, the relationship between the structure of the catalyst and its 
Table 1 Effect of the side arms of the catalyst in the reaction of 2-nitropropane and chalcone

\begin{tabular}{cccccc}
\hline Entry & Catalyst & R group of the catalyst & Time (h) & Yield of 26a (\%) $^{\mathbf{a}}$ & ee (\%) $^{\mathbf{b}}$ \\
\hline 1 & $\mathbf{1 a}$ & $n-\mathrm{C}_{4} \mathrm{H}_{9}$ & 40 & 41 & 48 \\
2 & $\mathbf{1 b}$ & $\mathrm{CH}_{2} \mathrm{C}_{6} \mathrm{H}_{5}$ & 22 & 39 & 46 \\
3 & $\mathbf{1 c}$ & $\left(\mathrm{CH}_{2}\right)_{2} \mathrm{OH}$ & 20 & 51 & 63 \\
4 & $\left(\mathrm{CH}_{2}\right)_{3} \mathrm{OH}$ & 28 & 53 & 87 \\
5 & $\mathbf{1 d}$ & $\left(\mathrm{CH}_{2}\right)_{3} \mathrm{OCH}_{3}$ & 40 & 52 & 90 \\
6 & $\mathbf{1 e}$ & $\left(\mathrm{CH}_{2}\right)_{4} \mathrm{P}(\mathrm{O})\left(\mathrm{OC}_{2} \mathrm{H}_{5}\right)_{2}$ & 48 & 39 & 83 \\
7 & $\mathbf{1 f}$ & $\left(\mathrm{CH}_{2}\right)_{2} \mathrm{P}(\mathrm{O})\left(\mathrm{C}_{6} \mathrm{H}_{5}\right)_{2}$ & 12 & 41 & 74 \\
8 & $\mathbf{1 g}$ & $\left(\mathrm{CH}_{2}\right)_{3} \mathrm{P}(\mathrm{O})\left(\mathrm{C}_{6} \mathrm{H}_{5}\right)_{2}$ & 14 & 32 & 77 \\
9 & $\mathbf{1 h}$ & $\left(\mathrm{CH}_{2}\right)_{4} \mathrm{P}(\mathrm{O})\left(\mathrm{C}_{6} \mathrm{H}_{5}\right)_{2}$ & 10 & 43 & 95 \\
\hline
\end{tabular}

${ }^{\mathrm{a}}$ Based on isolation by preparative TLC; ${ }^{\mathrm{b}}$ Enantioselectivities were determined by ${ }^{1} \mathrm{H}$ NMR spectroscopy in the presence of Eu(hfc) ${ }_{3}$ as a chiral shift reagent; the $(+)-(R)$-antipode of the Michael adduct 26 was formed

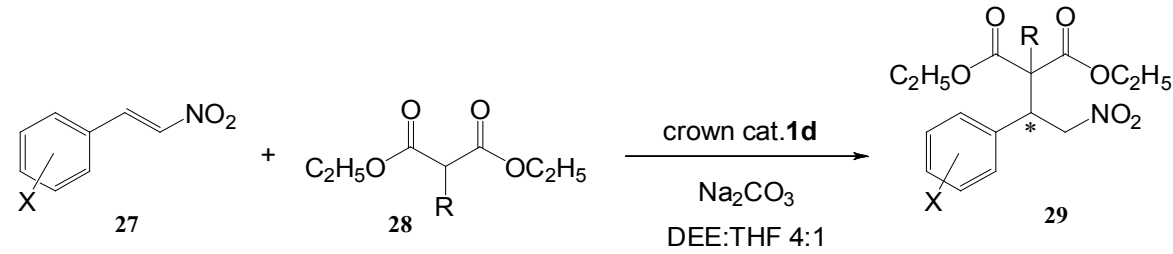

Fig. 4 Asymmetric addition of diethylmalonates $(\mathbf{2 8})$ to $\beta$-nitrostyrenes

effect was studied. The L-arabinose-based lariat ethers (4) generated 61-64\% enatiomeric excess (ee) in this reaction [9]. The D-glucopyranoside-(6) and D-mannopyranoside-(7) based macrocycles incorporating a pyridine-ring induced ee values of $72 \%$ and $67 \%$, respectively [11]. Using crown ethers comprising an $\alpha$-D-glucopyranoside unit (1), formation of the $(+)-R$ enantiomer was preferred, while applying $\alpha$-D-mannose-based catalysts (2), the (-)-S enantiomer was in excess. The monoaza-15-crown-5 type lariat ethers annelated to the methyl 4,6- $O$-benzylidene- $\alpha$ D-glucopyranoside unit (1) proved to be the most efficient catalysts. The effect of different $N$-substituents (R) could be observed from the results of the reaction carried out in the presence of lariat ether 1. A few experiments selected are shown in Table 1. The enantioselectivities were better with the catalysts having hydroxyl/methoxy group (entries 3-5) or a $P$-function (entries 6-9) at the end of the side arm, as compared to the cases with alkyl and arylalkyl groups at the end (entries 1-2). The best result (95\% ee) was obtained with the catalyst containing a $\mathrm{Ph}_{2} \mathrm{P}(\mathrm{O})$ $\left(\mathrm{CH}_{2}\right)_{4}$ substituent (1i). The chain length of substituents is of crucial importance. There is an optimum length for the hydrocarbon spacer connecting the $\mathrm{MeO}$ or $\mathrm{Ph}_{2} \mathrm{P}(\mathrm{O})$ moiety to the nitrogen atom of the azacrown ring. Among the catalysts tested, lariat ether 1e with a three carbon atom spacer $\left[\left(\mathrm{CH}_{2}\right)_{3}-\mathrm{OCH}_{3}\right]$ and macrocycle 1i with a four carbon atom chain $\left[\left(\mathrm{CH}_{2}\right)_{4}-\mathrm{P}(\mathrm{O}) \mathrm{Ph}_{2}\right]$ proved to be the best ( $90 \%$ ee and $95 \%$ ee, respectively) [5].

The asymmetric induction depends strongly on the nature of the $\mathrm{Ar}^{1}$ and $\mathrm{Ar}^{2}$ substituents of the $\alpha, \beta$-enone as well. In the presence of $\mathbf{1 d}\left[\mathrm{R}=\left(\mathrm{CH}_{2}\right)_{3} \mathrm{OH}\right]$, the substituents in the aromatic ring of the chalcone $\left(\mathrm{CH}_{3}, \mathrm{OCH}_{3}, \mathrm{NO}_{2}, \mathrm{Cl}, \mathrm{F}\right)$ resulted in a decrease in the optical yield (14-68\% ee), as compared to the case with the unsubstituted chalcone 26a (87\% ee). From among the $\alpha, \beta$-enones analogue to chalcone, the 1-naphthyl derivative ( $\mathrm{Ar}^{1}=1$-naphthyl-, $\left.\mathrm{Ar}^{2}=\mathrm{Ph}\right)$ and trans-crotonophenone derivative $\left(\mathrm{Ar}^{1}=\mathrm{Ph}, \mathrm{Ar}^{2}=\mathrm{Me}\right)$ were formed with the highest ee value (87\% and $76 \%$, respectively) $[5,13]$.

Another Michael reaction, the conjugate addition of substituted diethylmalonates $\mathbf{2 8}$ to $\beta$-nitrostyrenes $\mathbf{2 7}$ was carried out in a (1:4) mixture of THF-ether as the solvent in the presence of dry $\mathrm{Na}_{2} \mathrm{CO}_{3}$ (used in two-fold excess) employing $15 \mathrm{~mol} \%$ of the crown ether (Fig. 4). The (-)-(S) enantiomer of compound 29 was formed in the presence of catalyst 1d [14-15].

It was found that the $\alpha$-substituents of diethylmalonate influenced the extent of asymmetric induction. The results on the addition of a few $\alpha$-substituted diethyl malonate to $\beta$-nitrostyrene were summarized in Table 2 (Entries 1-5).

As compared to the unsubstituted product 29a, the substituted derivatives were formed in higher ee values. The methyl-, butyl-, OAc and NHAc derivatives (29b, 29c, 29d and 29e) were obtained in ee values of $42 \%, 22 \%, 29 \%$ and $99 \%$, respectively. The ee value of $99 \%$ detected in the reaction of acetamidomalonate is indeed considerable and refers to the role of the $\mathrm{NH}$ group in the asymmetric induction. It was found that the substituents of nitrostyrene also influenced the enantioselectivity. The results of the reaction of a few chloro-nitrostyrenes and nitro-substituted derivatives are shown in Table 2 (entries 6-9). It can be seen that the 4-chloro and the 4-nitro substituted products (29h and 29i) were obtained in the highest (97-99\%) ee, in a yield of $65 \%$ and $78 \%$, respectively [15].

The Darzens condensation taking place between aromatic $\alpha$-chloro-carbonyl compounds (30) and aromatic aldehydes 
Table 2 Addition of diethylmalonates $\mathbf{2 8}$ to $\beta$-nitrostyrenes $\mathbf{2 7}$ in the presence of catalyst $\mathbf{1 d}$

\begin{tabular}{|c|c|c|c|c|c|c|}
\hline Entry & Product & $\mathbf{R}$ & $\mathbf{X}$ & Time (h) & Yield of $29(\%)^{a}$ & ee $(\%)^{b}$ \\
\hline 1 & 29a & $\mathrm{H}$ & $\mathrm{H}$ & 20 & 61 & 20 \\
\hline 2 & $29 b$ & $\mathrm{CH}_{3}$ & $\mathrm{H}$ & 48 & 67 & 42 \\
\hline 3 & $29 c$ & $n-\mathrm{C}_{4} \mathrm{H}_{9}$ & $\mathrm{H}$ & 100 & 50 & 22 \\
\hline 4 & 29d & $\mathrm{NHCOCH}_{3}$ & $\mathrm{H}$ & 20 & 69 & 29 \\
\hline 5 & $29 \mathrm{e}$ & $\mathrm{NHCOCH}_{3}$ & $\mathrm{H}$ & 3 & 60 & 99 \\
\hline 6 & $29 f$ & $\mathrm{NHCOCH}_{3}$ & $2-\mathrm{Cl}$ & 4 & 76 & 67 \\
\hline 7 & $29 \mathrm{~g}$ & $\mathrm{NHCOCH}_{3}$ & $3-\mathrm{Cl}$ & 4 & 61 & 72 \\
\hline 8 & $29 h$ & $\mathrm{NHCOCH}_{3}$ & $4-\mathrm{Cl}$ & 4 & 65 & 99 \\
\hline 9 & $29 \mathrm{i}$ & $\mathrm{NHCOCH}_{3}$ & $4-\mathrm{O}_{2} \mathrm{~N}$ & 6 & 78 & 97 \\
\hline
\end{tabular}

${ }^{\mathrm{a}}$ Based on isolation by preparative TLC; ${ }^{\mathrm{b}}$ Determined by chiral HPLC analysis, the (-)- $(S)$ enantiomer was formed.

Table 3 Asymmetric Darzens condensations in the presence of catalyst 1d

\begin{tabular}{|c|c|c|c|c|c|}
\hline Entry & $A \mathbf{r}^{1}$ & $\mathbf{A} \mathbf{r}^{2}$ & Time (h) & Yield of $32(\%)^{a}$ & ee $(\%)^{b}$ \\
\hline 1 & $\mathrm{C}_{6} \mathrm{H}_{5}$ & $\mathrm{Ph}$ & 1 & 74 & 71 \\
\hline 2 & $4-\mathrm{C}_{6} \mathrm{H}_{5}-\mathrm{C}_{6} \mathrm{H}_{4}$ & $\mathrm{Ph}$ & 1 & 54 & 96 \\
\hline 3 & $4-\mathrm{C}_{6} \mathrm{H}_{5}-\mathrm{C}_{6} \mathrm{H}_{4}$ & $2-\mathrm{Cl}-\mathrm{C}_{6} \mathrm{H}_{4}$ & 1 & 71 & 84 \\
\hline 4 & $4-\mathrm{C}_{6} \mathrm{H}_{5}-\mathrm{C}_{6} \mathrm{H}_{4}$ & $4-\mathrm{H}_{3} \mathrm{C}-\mathrm{C} 6 \mathrm{H}_{4}$ & 1 & 54 & 67 \\
\hline 5 & $4-\mathrm{C}_{6} \mathrm{H}_{5}-\mathrm{C}_{6} \mathrm{H}_{4}$ & 2-Naphthyl & 2 & 56 & 74 \\
\hline 6 & Furan-2-yl & $2-\mathrm{Cl}-\mathrm{C}_{6} \mathrm{H}_{4}$ & 5 & 77 & 70 \\
\hline 7 & Furan-2-yl & 4-Cl- $\mathrm{C}_{6} \mathrm{H}_{4}$ & 3 & 67 & 62 \\
\hline 8 & Tiophen-2-yl & $\mathrm{Ph}$ & 5 & 63 & 71 \\
\hline 9 & Tiophen-2-yl & $2-\mathrm{H}_{3} \mathrm{C}-\mathrm{C}_{6} \mathrm{H}_{4}$ & 3 & 79 & 68 \\
\hline 10 & Tiophen-2-yl & Piperonyl & 5 & 57 & 86 \\
\hline 11 & Pyrrol-2-yl & 1-Naphthyl & 1 & 42 & 51 \\
\hline
\end{tabular}

${ }^{a}$ Based on isolation by preparative TLC; products $\mathbf{3 2}$ had a negative specific rotation; ${ }^{\mathrm{b}}$ Determined by ${ }^{1} \mathrm{H}$ NMR spectroscopy

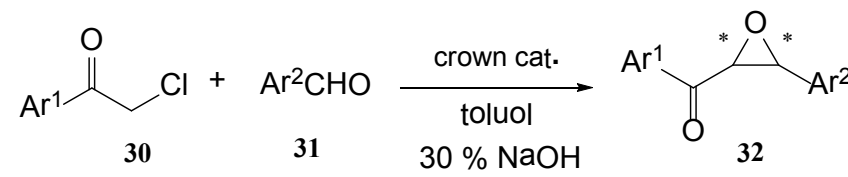

Fig. 5 Darzens condensation of aromatic $\alpha$-chloro-carbonyl compounds and aldehydes

(31) was performed in toluene solution using $30 \% \mathrm{NaOH}$ at $22^{\circ} \mathrm{C}$ and took place in a stereoselective manner in the presence of chiral catalysts (Fig. 5). The trans-epoxyketone (32) was obtained in general in a diastereomeric excess (de) of $>98 \%$, with a configuration of (-)-(2R,3S) [5, 8, 14, 16-18].

The aromatic unit $\left(\mathrm{Ar}^{1}\right)$ of the $\alpha$-chloro-carbonyl compounds (30) were phenyl-, 2-furyl-, 2-thiophenyl-, 2-pyrroyl. Benzaldehyde, substituted benzaldehydes, 1- and 2-naphthaldehydes and piperonal formed the choice of the aldehyde reactants. The use of D-glucose-based lariat ether $\mathbf{1 d}\left(\mathrm{R}=\left(\mathrm{CH}_{2}\right)_{3} \mathrm{OH}\right)$ as the catalyst gave the best results. The results of the reaction of a few aromatic aldehydes in the presence of the catalyst $1 \mathbf{d}$ were summarized in Table $3[14,16]$.

The maximum selectivity (96\% ee) was detected in the reaction of 4-phenyl- $\alpha$-chloroacetophenone with benzaldehyde (Table 3, entry 2). The substituents of benzaldehyde used as the reactants had a significant impact on the yield and enantioselectivity (Table 3, entries 3-4 and 6-9) [17]. The $\alpha, \beta$-epoxyketones with a furan (Table 3, entries 6-7) or a thiophene (Table 3, entries 8-10) moiety were obtained in good enantioselectivities (up to $86 \%$ ee) as well as excellent diastereoselectivities (up to $98: 2$ ), but the epoxyketone with a pyrrole ring was formed in a low yield and enantioselectivity (Table 3 , entry 11). The mannose-based crown ethers $\mathbf{2}$ generated lower enantioselectivities and promoted the formation of the enantiomer with a positive optical rotation [16].

The absolute configuration of a few epoxyketones was determined by single crystal X-ray analysis. As an example, we show the ORTEP representation of the epoxyketone obtained in the reaction of 4-phenyl- $\alpha$-chloroacetophenone with 2-chlorobenzaldehyde. According to this, the absolute configuration is $2 R, 3 S$ (Fig. 6). It is reasonable to assume that the other epoxyketone derivatives with negative optical rotation also possess the same $2 R, 3 S$ absolute configuration [17].

The reaction of cyclic $\alpha$-chloroketones with aromatic aldehydes was studied under the conditions described above in the presence of catalysts 1 and 2 . The reactions of 2-chloro1-indanone (33) and 2-chloro-1-tetralone (34) with various aromatic aldehydes (31) were completed after a stirring of 20-40 minutes at $0^{\circ} \mathrm{C}$ in the presence of catalyst 1 (Fig. 7). The 


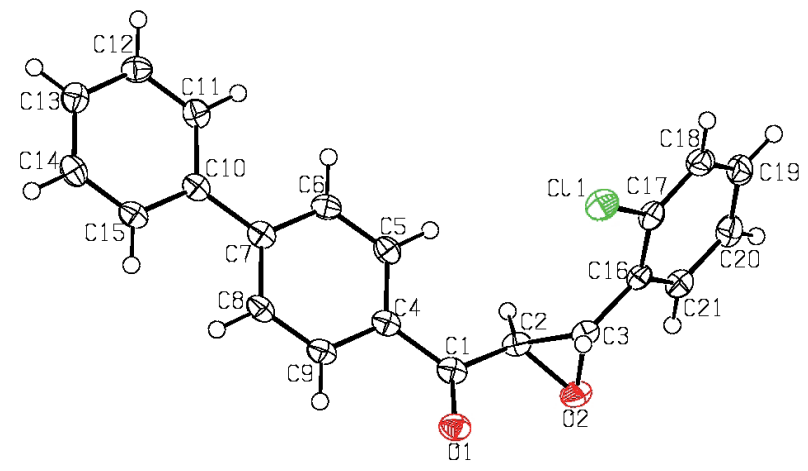

Fig. 6 ORTEP representation of (2R,3S)-2,3-epoxy-1-(biphen-4-yl)-3-(2-chloro-phenyl)propan-1-one

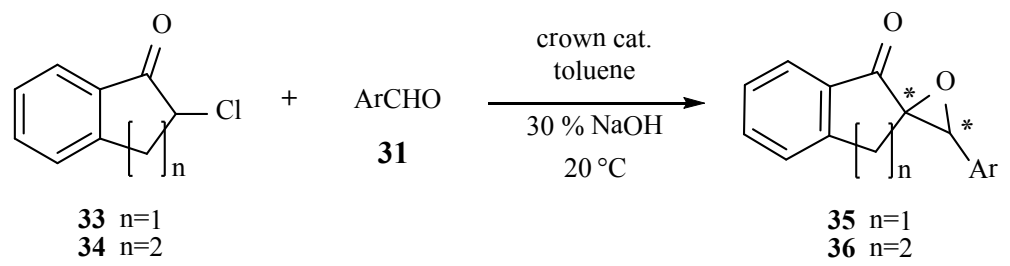

Fig. 7 Darzens condensation of cyclic $\alpha$-chloroketones (33 and 34) with aromatic aldehydes in the presence of catalyst $\mathbf{1 d}$

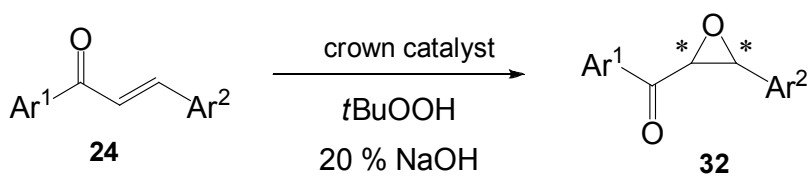

Fig. 8 Asymmetric epoxidation of $\alpha, \beta$-enones

trans-epoxyketones (35 and 36) were obtained in good yields with high diastereoselectivites (de of $>98 \%$ ) and with moderate to good enantioselectivities [14, 17].

The reaction of 2-chloro-1-indanone (33) and benzaldehyde gave epoxyketone 35a $(\mathrm{Ar}=\mathrm{Ph})$ in a yield of $59 \%$ and in an ee value of $65 \%$. Among the substituted benzaldehydes, the best results were obtained in the reaction with 2-chlorobenzaldehyde; in this case, product $\mathbf{3 5} \mathbf{b}\left(\mathrm{Ar}=2-\mathrm{Cl}-\mathrm{C}_{6} \mathrm{H}_{4}\right)$ was formed in an ee of $85 \%$. It was found that the change in the ring size (replacing the 5 -membered ring by a 6 -membered ring, i.e. going from 33 to 34 , respectively) had a dramatic impact on the isolated yields and optical purities. In the reaction of 2-chloro-1-tetralone (34) with benzaldehyde, epoxyketone $\mathbf{3 6 a}(\mathrm{Ar}=\mathrm{Ph})$ was formed in a yield of $84 \%$ and in an enantioselectivity of $74 \%$. The effect of the substituents of the benzaldehyde was evaluated. The substituted derivatives were formed in lower (32-70\%) ee values. In the case of both cyclic $\alpha$-chloroketones, the configurations of the stereogenic centers were found to be $2 R, 3$ ' $S$ on the basis of single crystal X-ray analysis. The mannose-based crown ethers 2 generated lower ee values and the chiral epoxyketones were formed with a $2 S, 3^{\prime} R$ configuration. As an example, in the presence of catalyst $2\left(\mathrm{R}=\left(\mathrm{CH}_{2}\right)_{3} \mathrm{OH}\right)$ products $35 \mathbf{b}$ and 36a were formed in ee values of $64 \%$ and $61 \%$, respectively [14, 17].

The epoxidation of $\alpha, \beta$-enones (24) was carried out with 2 equivalents of tert-butyl hydroperoxide (TBHP) at $0^{\circ} \mathrm{C}$ in toluene, in a liquid-liquid two-phase system, employing $20 \%$ aq. $\mathrm{NaOH}$ (3.5 eq.) as the base and $7 \mathrm{~mol} \%$ of lariat ether as the catalyst [5]. The reactions were complete after 1-8 $\mathrm{h}$ and led to variable yields (38-86 \%). The trans-epoxyketone (32) was obtained in all experiments (Fig. 8).

The relationship between the structure of the catalyst and its effect was studied in the epoxidation of chalcone $\left(\mathrm{Ar}^{1}=\mathrm{Ph}\right.$, $\mathrm{Ar}^{2}=\mathrm{Ph}$ ). It was found that the yield and enantioselectivity are significantly affected by the type of the monosaccharide moiety and the $N$-substituents of the crown ring. Comparing the enantioselectivity obtained in the presence of the catalysts with different monosaccharide units 1-10, the D-glucose-based lariat ethers (1) gave the best results. The effect of the different side arms have been studied in the case of this catalyst (1) (Table 4). Using glucose-based crown ethers $\mathbf{1}$, formation of the (-)-(2R,3S) enantiomer was preferred, while applying mannose-based $\mathbf{2}$ as the catalysts, the $(+)-(2 S, 3 R)$ antipode was in excess [5].

The best results (94\% and $81 \%$ ee) were obtained applying crown ethers with $\gamma$-hydroxypropyl and $\beta$-hydroxyethyl substituents (as in 1d and 1c), respectively. Using the $\delta$-hydroxybutyl derivative (1f), the ee was $41 \%$. It can be concluded that the length of the chain connecting the hydroxyl group to the nitrogen atom plays an important role in the asymmetric induction; a chain of three carbon atoms is the optimum. It is also interesting that the methylation of the hydroxyl group in $\mathbf{1 d}$ resulted in a dramatic decrease in the enantioselectivity as was demonstrated by the ee $23 \%$ obtained with 1e. It is clear that the hydrophilic hydroxyl substituents $\left.\left[\left(\mathrm{CH}_{2}\right)_{\mathrm{n}} \mathrm{OH}\right]\right)$ promote the transport of the catalyst between the two phases (toluene and water), while the lipophilic $\left(\mathrm{CH}_{2}\right)_{\mathrm{n}} \mathrm{OMe}$ substituents have an opposite effect [5].

It was found that the position of the substituents in the aromatic ring of the chalcone had a great impact on the yield and 
Table 4 Effect of the $N$-side arms of the catalyst 1 in the epoxidation of chalcone $\left(\mathbf{2 4}, \mathrm{A}^{1}=\mathrm{A}^{2}=\mathrm{Ph}\right)$

\begin{tabular}{|c|c|c|c|c|c|}
\hline Entry & Catalyst & $\mathbf{R}$ & Time (h) & Yield of $32(\%)^{a}$ & ee $(\%)^{b}$ \\
\hline 1 & $1 \mathbf{a}$ & $\left(\mathrm{CH}_{2}\right)_{2} \mathrm{OH}$ & 1 & 65 & 81 \\
\hline 2 & 1b & $\left(\mathrm{CH}_{2}\right)_{3} \mathrm{OH}$ & 1 & 82 & 94 \\
\hline 3 & $1 \mathrm{c}$ & $\left(\mathrm{CH}_{2}\right)_{3} \mathrm{OCH}_{3}$ & 2 & 61 & 23 \\
\hline 4 & 1d & $\left(\mathrm{CH}_{2}\right)_{4} \mathrm{OH}$ & 1 & 65 & 41 \\
\hline
\end{tabular}

${ }^{a}$ Based on isolation by preparative TLC; ${ }^{\mathrm{b}}$ Enantioselectivities were determined by ${ }^{1} \mathrm{H}$ NMR spectroscopy; the (-)-(2R,3S)-antipode of the epoxyketone $\mathbf{3 2}$ was formed

Table 5 Asymmetric epoxidation of chalcone, substituted chalcones and chalcone analogues in the presence of the catalyst 1d

\begin{tabular}{|c|c|c|c|c|c|c|}
\hline Entry & $A \mathbf{r}^{1}$ & $A r^{2}$ & Time (h) & $\begin{array}{c}\text { Yield of } 32 \\
(\%)^{\mathrm{a}}\end{array}$ & {$[\alpha]_{D}^{22 \mathrm{~b}}$} & ee $(\%)^{c}$ \\
\hline 1 & $\mathrm{Ph}$ & $\mathrm{Ph}$ & 1 & 82 & -196 & 94 \\
\hline 2 & 4-Cl- $\mathrm{C}_{6} \mathrm{H}_{5}$ & $\mathrm{Ph}$ & 2 & 71 & -182 & 97 \\
\hline 3 & $4-\mathrm{H}_{3} \mathrm{CO}-\mathrm{C}_{6} \mathrm{H}_{5}$ & $\mathrm{Ph}$ & 3 & 58 & -199 & 95 \\
\hline 4 & $3-\mathrm{O}_{2} \mathrm{~N}-\mathrm{C}_{6} \mathrm{H}_{5}$ & $\mathrm{Ph}$ & 1 & 55 & -147 & 99 \\
\hline 5 & But & $\mathrm{Ph}$ & 16 & 86 & -239 & 90 \\
\hline 6 & 1-Naphthyl & $\mathrm{Ph}$ & 10 & 64 & -188 & 67 \\
\hline 7 & 2-Naphthyl & $\mathrm{Ph}$ & 3 & 30 & -138 & 87 \\
\hline 8 & But & 1-Naphthyl & 12 & 60 & -48 & 85 \\
\hline 9 & But & 2-Naphthyl & 12 & 52 & -253 & 92 \\
\hline 10 & N-Methyl-2-pyrroyl & $\mathrm{Ph}$ & 46 & 80 & -210 & 79 \\
\hline
\end{tabular}

${ }^{\mathrm{a}}$ Based on isolation by preparative TLC; ${ }^{\mathrm{b}}$ Enantioselectivities were determined by ${ }^{1} \mathrm{H}$ NMR spectroscopy; the (-)-(2R,3S)-antipode of the epoxyketone 32 was formed

enantioselectivity. The lowest enantioselectivities (62-83\% ee) were found in the case of the ortho-substituted model compounds, while the highest ee values (ee of 95-99\%) were obtained in the case of para-substituted models (good results of a few experiments in Table 5, entries 1-4). The epoxidation of the chalcone analogues are summarized in Table 5 (entries 5-10). The best enantiomeric excess values were obtained for the epoxyketone with $\mathrm{R}^{1}=$ But and $\mathrm{R}^{2}=\mathrm{Ph}$, (90\% ee) or $\mathrm{R}^{1}=$ But and $\mathrm{R}^{2}=2$-naphthyl (92\% ee) [19].

Finally, two glucopyranoside-based crown ethers, with acridine fluorescent signalling units were synthesized, the 15-membered ligand 12a and the 21-membered ligand $\mathbf{1 2 b}$. Their complexation properties toward alkali and alkali earth metal ions, and their enantioselectivity towards chiral ammonium salts were studied by absorption and fluorescence spectroscopic experiments. Macrocycle 12a formed 1:1 complexes with all the metal ions selected and the stability constants were low (lg $\mathrm{K}<2.3$ ). The cavity-size of $12 \mathrm{~b}$ only afforded the complexation of organic ammonium ions. It showed chiral discrimination in case of all the four ammonium salts used as model guest compounds. The highest enantioselectivity $(\mathrm{K}(R) / \mathrm{K}(S) \sim 3)$ was observed in case of the enantiomers of phenylethyl-ammonium (PEA) perchlorate. Ligand $\mathbf{1 2 b}$ forms much more stable complexes with metal ions, the highest stability constant was obtained for the $\mathrm{Ca}^{2+}$ complex $(\lg \mathrm{K}=6.15)$. The coordination of metal ions by species $\mathbf{1 2} \mathbf{b}$ was accompanied by a marked fluorescence enhancement, whereas the binding of ammonium ions by the same ligand resulted in significant fluorescence quenching [12].

\section{Summary}

We have synthesized a variety of chiral crown ethers containing one sugar unit in annelation with the macrocyclic ring from various monosaccharides such as D-glucose, D-mannose, D-galactose, D-altrose, 2-deoxy-D-ribo-hexopyranoside, L-arabinose and from sugar alcohols as L-treitol, D-mannitol. A few representatives of the monosaccharide-based crown ethers induced a considerable asymmetric induction in certain reactions. On the basis of our experiences, it can be concluded that in the case of monoaza-15-crown-5 lariat ethers incorporation of a D-glucose moiety results in the most efficient catalysts. The glucose-based catalysts with $\left(\mathrm{CH}_{2}\right)_{3} \mathrm{OH}$ substituent on the nitrogen atom (1d) showed the best results regarding the enantioselectivity. In the reaction of 2-nitropropane with chalcone and chalcone analogue $\alpha, \beta$-enones $48-95 \%$ ee values were measured. Addition of diethylmalonates to $\beta$-nitrostyrenes gave the Michael adducts in an enantioselectivity of 20-97\%. The epoxyketones were obtained in 51-96 \% ee values in Darzens condensations and in 67-99 \% ee values in epoxidation of $\alpha, \beta$-enones in the presence of catalyst 1d. The development of novel catalysts is of practical importance, as the lariat ethers can be utilized in a variety of phase transfer catalytic reactions, a part of which is to be explored. 


\section{References}

[1] Shioiri, T. "Chiral phase transfer catalysis." In: Sasson, Y., Neumann, R. (eds). Handbook of Phase-Transfer Catalysis. London: Blackie Academic \& Professional. 1997. DOI: 10.1007/978-94-009-0023-3_14

[2] O' Donnell, M. J. "Asymmetric Phase - Transfer Reactions." In: Ojima, I. (ed) Catalytic Asymmetric Synthesis. New York : VCH. 2000. DOI: $10.1002 / 0471721506 . \operatorname{ch} 23$

[3] Marouka, K. "Asymmetric Phase Transfer Catalysis." Weinheim: Wiley-VCH Verlag GmbH \& Co. KgaA. 2008. DOI: $10.1002 / 9783527622627$

[4] Stoddart, J. F. "Chiral crown ethers." Topics in Stereochemistry. 17. pp. 207-288. 1987.

DOI: $10.1002 / 9780470147269 . \operatorname{ch} 3$

[5] Bakó, P., Keglevich, G., Rapi, Z. "Asymmetric Phase Transfer Catalyzed by Chiral Crown Ethers Derived from Monosaccharides." Letters in Organic Chemistry. 7 (8). pp. 645-656. 2010. DOI: $10.2174 / 157017810793811669$

[6] Gokel, G. W. "Lariat ethers - from simple sidearms to supramolecular systems." Chemical Society Reviews. 21 (1). p. 39-47. 1992. DOI: $10.1039 / \mathrm{cs} 9922100039$

[7] Bakó, P., Tőke, L. "Novel Monoaza- and Diazacrown Ethers Incorporting Sugar Units and Their Extraction Ability towards Picrate Salts." Journal of Inclusion Phenomena and Molecular Recognition in Chemistry. 23 (3). pp. 195-201. 1995. DOI: $10.1007 /$ bf00709577

[8] Makó, A., Szöllősy, Á., Keglevich, G., Menyhárd, D. K., Bakó, P., Töke, L. "Synthesis of methyl- $\alpha$-D-glucopyranoside-based azacrown ethers and their application in enantioselective reactions." Monatshefte für Chemie - Chemical Monthly. 139 (5). pp. 525-535. 2008. DOI: 10.1007/s00706-007-0799-7

[9] Szabó, T., Rapi Z., Keglevich, G., Szöllősy, Á., Drahos, L., Bakó, P. "Synthesis of L-arabinose-based crown ethers and their application as enantioselective phase transfer catalyst." Arkivoc. 2012 (8). pp. 36-48. 2012.

DOI: $10.3998 /$ ark.5550190.0013.804

[10] Rapi, Z., Bakó, P., Keglevich, G., Szöllősy, Á., Drahos, L., Hegedűs, L. "Synthesis of ribose and altrose based azacrown ethers and their application in an asymmetric Michael addition." Carbohydrate Research. 365. pp. 61-68. 2013.

[11] Makó, A., Bakó, P., Szöllősy, Á., Bakó, T., Peltz, C., Keglevich, P. "Synthesis of chiral pyridino-15-crown-5 type ligands containing $\alpha$-Dhexapyranoside unit and their application in asymmetric synthesis." Arkivoc. 2009 (7). pp. 165-179. 2009.

DOI: $10.3998 /$ ark. 5550190.0010 .716
[12] Rapi, Z., Bakó, P., Keglevich, G., Baranyai, P., Kubinyi, M., Varga, O. "Synthesis and optical characterization of $\alpha$-D-glucose-based fluorescent crown ethers containing an acridine unit." Journal of Inclusion Phenomena and Macrocyclic Chemistry. 2014. DOI: $10.1007 / \mathrm{s} 10847-014-0384-8$

[13] Makó, A., Rapi, Z., Drahos, L., Szöllősy, Á., Keglevich, G., Bakó, P., "Enantioselective Michael Addition of 2-Nitropropane to Substituted Chalcone and Chalcone Analogues Catalyzed by Chiral Crown Ethers Incorporating an $\alpha$-D-Glucose or an $\alpha$-D-Mannose Unit." Letters in Organic Chemistry. 7 (6). pp. 919-925. 2010. DOI: 10.2174/157017810791824865

[14] Bakó, P., Rapi, Z., Keglevich, G., Szabó, T., Sóti, P. L., Vigh, T., Grün, A., Holczbauer, T. "Asymmetric C-C bond formation via Darzens condensation and Michael addition using monosaccharide-based chiral crown ethers." Tetrahedron Letters. 52 (13). p. 1473-1476. 2011. DOI: 10.1016/j.tetlet.2011.01.094

[15] Rapi, Z., Démuth, B., Keglevich, G., Grủn, A., Drahos, L., Sóti, P. L., Bakó, P. "Enantioselective Michael addition of malonates to aromatic nitroalkenes catalyzed by monosaccharide-based chiral crown ethers." Tetrahedron: Asymmetry. 25 (2). pp. 141-147. 2014.

DOI: $10.1016 / j$.tetasy.2013.12.007

[16] Rapi, Z., Szabó, T., Keglevich, G., Szöllősy, Á., Drahos, L., Bakó, P. "Enantioselective synthesis of heteroaromatic epoxyketones under phase-transfer catalysis using D-glucose- and D-mannose-based crown ethers." Tetrahedron: Asymmetry. 22 (11). pp. 1189-1196. 2011. DOI: $10.1016 /$ j.tetasy.2011.07.001

[17] Rapi, Z., Bakó, P., Keglevich, G., Szöllősy, Á., Drahos, L., Botyánszki, A., Holczbauer, T. "Asymmetric phase transfer Darzens reaction using D-glucose- and D-mannose-based chiral crown ethers as the catalyst." Tetrahedron: Asymmetry. 23 (6-7). pp. 489-496. 2012. DOI: $10.1016 /$ j.tetasy.2012.04.006

[18] Bakó, P., Rapi, Z., Keglevich, G. "Catalytic Asymmetric Darzens Reactions." Current Organic Synthesis. 11 (3). pp. 361-376. 2014. DOI: 10.2174/15701794113106660073

[19] Makó, A., Rapi, Z., Keglevich, G., Szöllősy, Á., Drahos, L., Hegedủs, L., Bakó, P. "Asymmetric epoxidation of substituted chalcones and chalcone analogues catalyzed by $\alpha$-D-glucose- and $\alpha$-D-mannose-based crown ethers." Tetrahedron: Asymmetry. 21 (8). pp. 919-925. 2010. DOI: $10.1016 / j$.tetasy.2010.05.009 